\title{
On Wittgenstein's Concept of 'Following a Rule' and Its Implication for the Philosophy of Mathematics
}

\author{
Akio KIKAI*
}

\begin{abstract}
Kripke's monumental work on Wittgenstein made it possible to think about the global structure of Philosophical Investigations (P.I.) and to suppose the existence of systematic thinking in that book by emphasizing the importance of so called rule following considerations for later Wittgenstein. On the other hand, however, Kripke's work seems to have misled us to a wrong assumption that the central theme in these considerations is not the concept of rules but that of meaning. I learned from my past systematic investigation of Wittgenstein's texts, including both P.I. and his other texts that reveal us the specific contexts in which his huge considerations concerning rules were conducted in 1930's and 1940 's, that the problems concerning rules play the central role in the formation of matured philosophy of later Wittgenstein exhibited in P.I.

In this paper, I would like to show 1) Wittgenstein faced not one but three problems concerning the concept of 'rules of a language game' in the initial 188 sections of P.I., one of which is the paradox of rules, 2) he solved these problems in $\S \S 198-243$ of P.I. by presenting a new concept of 'following a rule', which is supposed to be prior to any explicit rules with respect to both existence and meaning, 3) 'following a rule' is a generic name for primitive linguistic practices such as counting or ordering, out of which all our linguistic practices or language games are constructed, 4) according to Wittgenstein's new understanding of human linguistic practices based on the concept of 'following a rule', any forms of Platonism as well as formalism in mathematics cannot be correct.
\end{abstract}

\section{Introduction}

Kripke's monumental work on Wittgenstein, ${ }^{1}$ whose $25^{\text {th }}$ anniversary this paper ${ }^{2}$ is dedicated to, has set the basic direction of the study of Philosophical Investigations $^{3}$ ever since by presenting two striking assertions. The first assertion is that there

${ }^{*}$ University of Tsukuba (kikai@sakura.cc.tsukuba.ac.jp)

${ }^{1}$ Kripke (1982).

${ }^{2}$ The original draft of this paper was read at the International Wittgenstein Workshop at the University of Tokyo, June 2, 2007. I would like to express my great gratitude to Brendan Wilson (University of Tokyo) for his philosophical as well as stylistic comments on my draft.

${ }^{3}$ When quoting from Philosophical Investigations (P.I.), I use Anscombe's English 
exists a clear global structure in this extraordinary book of Wittgenstein, and the second is that the central topic governing its whole discussions is that of rule-following. Some have rejected and others have accepted these claims. ${ }^{4}$ In any case, it is clear that how we take them necessarily determines our understanding of Philosophical Investigations in the most fundamental way. I myself find them correct, and have been guided by them in my past study of this text. On the other hand, as I studied Wittgenstein's texts and thoughts more, I came to feel that the exact nature of his problem and solution exhibited in this text is somewhat different from what Kripke presented. ${ }^{5}$ For example, while Kripke took Wittgenstein's fundamental problem as a meta-linguistic one about the nature of such an expression as 'to mean something by something', I think that formulating the problem this way prevents us from grasping its real scope. In a similar way, I think that to say Wittgenstein solved the problem by replacing the truth conditions for that expression with its assertability conditions seems to unjustifiably diminish the significance of his thoughts since it sounds as if he had tried to establish a new theory of meaning, which by no means is the case. ${ }^{6}$

translation (Wittgenstein (1958)), indicating section numbers, unless otherwise noted.

${ }^{4}$ Warren Goldfarb, for example, questions Kripke's interpretation of the global structure of P.I. (Goldfarb (1985), p.472) while Crispin Wright seems to accept it (C. Wright (1984), p.759). I am indebted to Matsuzaka (1995) for the initiation to the literature about Kripke's interpretation of Wittgenstein.

${ }^{5}$ My systematic interpretation of the whole course of Wittgenstein's philosophical thinking from 1912 to 1951 is presented in my book in Japanese (Kikai (2003)). The current paper is based on the part IV of that book.

${ }^{6}$ If we dare to ask "What is the theory of meaning for later Wittgenstein ?", the answer, I think, should be that it is a "theory" of "meaning as use" as the following famous passage of P.I. suggests.

For a large class of cases- though not for all- in which we employ the word "meaning" it can be defined thus: the meaning of a word is its use in the language. ( $\S$ 43)

What this means, however, is not that Wittgenstein tried to construct a theory of meaning in terms of use in any ordinary sense of the word "theory" but that the philosophical problems concerning the traditional concept of "meaning" were converted to those of "language game and its rules" for him thereafter. While Kripke enormously contributes to the production of the proper understanding of P.I., it is regrettable that his work directed the subsequent discussions about later Wittgenstein to a wrong, I think, direction because he concentrated on the problem of meaning, not that of rules.

That the series of discussions following Kripke's work tend to be focused not on the concept of rules but that of meaning is reflected on Paul Boghossian's following words in his 'survey' paper.

It would not be inappropriate to wonder at this point what all this has to do with the topic of rule-following? Where, precisely, is the connection between the concepts of meaning and content, on the one hand, and the concept of following a rule, on the other, forged? I shall argue that, in an important sense, the answer is 'nowhere', and hence that 'the rule-following considerations' is, strictly speaking, a misnomer for the discussion on offer. (Boghossian (1989), p.516) 
I think that there are not one, but several problems about rules and Wittgenstein solved them by presenting a completely new understanding of our linguistic activities. This solution has deep implications for many areas of philosophical thinking, especially for the philosophy of mathematics, which seems not to be sufficiently captured by Kripke's work. ${ }^{7}$

In the following, I would like to explore the nature and scope of Wittgenstein's problems about rules and his solution of them by taking a close look at his texts. ${ }^{8}$ Particularly I want to examine 1) how these problems developed in the thoughts of Wittgenstein, 2) what these problems exactly are, 3) what his solution of them in terms of 'following a rule' is and 4) what its implication for the philosophy of mathematics is. I consider my investigation not as a criticism of Kripke's work, but as a possible extension of it.

\section{1.}

Our first task is to explore the origin of Wittgenstein's analogy between language and game. Wittgenstein's recorded conversations with Friedrich Waismann, Moritz Schlick and other members of the Vienna Circle, published under the title of Ludwig Wittgenstein and the Vienna Circle, ${ }^{9}$ show that he very often talked and thought about a game and its rules in the period from 1929 to 1932. They also show that the source from which he borrowed this concept is the formalist philosophy of mathematics. In one conversation, for example, he says, "The truth in formalism is that every syntax can be conceived of as a system of rules of a game. I have been thinking about what Wyle may mean when he says that a formalist conceives of the

${ }^{7}$ If we think that the fundamental problem for Wittgenstein is that of meaning, we could find nothing specific in the cases of mathematical expressions since the question of the existence of meaning constituting facts is same for all kinds of expressions. It seems to me that this is why Kripke failed to capture the specifically mathematical significance of the paradox of rules. On the other hand, if we recognize that the real issue is that of rules, then the cases of mathematics come to have a specific significance since rules are indispensable to mathematics while we can separate the concept of rules and ordinary use of language because of the latter's vagueness. Thus, I think, Kripke's concentration on the problem of meaning and his failure to properly capture the mathematical implication of the paradox and its solution has a deep internal connection.

${ }^{8}$ In this paper, I make full use of textual and chronological information about P.I. derived from G.H. von Wright's work (von Wright (1982)) and my own research (Kikai (2003)). As for von Wright's work, the following two papers are fundamental for the proper understanding of P.I., i.e. "The Wittgenstein's Papers" (von Wright (1982), pp.35-62) and "The Origin and Composition of the Philosophical Investigations" (von Wright (1982), pp.111-136).

${ }^{9}$ Wittgenstein (1979). 
axioms of mathematics as like chess-rules." 10 In short, Wittgenstein seems to have started developing his analogy between language and game by borrowing the concept of a 'game and its rules' from the formalist philosophy of mathematics at this period, and he did so probably to use this analogy in describing our ordinary use of language in accordance with the picture of language depicted in the Tractatus. ${ }^{11}$ In the Tractatus, he described language as an entity having rigid logical forms, by means of which it serves us as the means of representing facts. However, the language as such is a system of fixed forms and structures that do not exist in the temporal and causal world while our actual uses of language, which include both production and understanding of sentences, always exist in the temporal and causal world. Therefore if we want to see our actual uses of language not as random phenomena without any order or regularities but as an actualization of these fixed logical forms, we need to connect our actual linguistic activities with these fixed forms by the mediation of something else. It is the formalist's concept of a 'game and its rules', I think, that served as such mediation for Wittgenstein at this period. According to this concept, mathematical activities like calculations or proofs are considered as activities governed by fixed rules of a game. Thus, if we are to consider the process of production and understanding of a sentence as a kind of mental calculation on the one hand, and regard calculation as game-like activities a la formalist on the other, we may regard our uses of language as game-like activities governed by the fixed rules representing the logical forms of language. This seems to be the thread of Wittgenstein's thoughts expressed in the texts of this period. For example, he says on the understanding of a sentence, "Understanding a word or a sentence is calculating." 12 About the relationship between a game and its rules, he says, "After all, the rules are instructions for playing the game and, as long as I can play, they must be all right." 13 And about the close connection among the concepts of calculation, game, and rule, he says, "It is clear that the question,' What is a calculation?' is exactly of the same kind as the one 'What is a game?' or 'What is a rule?", 14

At this point of our inquiry, I would like to direct the reader's attention to one important feature of Wittgenstein's thinking of this period indicated above. In those thoughts, he compares and connects two kinds of things. Things of the first kind are fixed entities such as logical forms of language or rules of a game. They are fixed, they don't move or change, they don't enter any causal processes. If you like, you may call them eternal Platonic objects. Things of the second kind are temporal activities of human beings such as speaking or playing a game. In his thinking about

\footnotetext{
${ }^{10}$ Wittgenstein (1979), p.103.

11 Wittgenstein (1922).

12 Wittgenstein (1979), p.168.

13 Wittgenstein (1979), p.125.

14 Wittgenstein (2000), MS.111, p.75, August 11, 1931, the translation is mine.
} 
their relationship, Wittgenstein clearly gives ontological priority to the first category of entities over the second. An activity is considered as a playing of a game only in so far as it is considered as governed by the specific rules of that game, and an activity is considered as a linguistic activity only in so far as it is considered as instantiating the logical form of a particular sentence. In this sense, Wittgenstein's thoughts on language and mathematics are clearly Platonistic at this period. His transition from the Tractatus to the Investigations involves nothing less than the reversal of this order of ontological priority and the complete negation of Platonism as well as of formalism. ${ }^{15}$ The problems concerning rules are those that were necessarily faced by him in this process.

2.

It is clear that Wittgenstein deepened and expanded his analogy between language and game so as to have developed his own concept of 'language game' by the time of The Brown Book. ${ }^{16}$ It is when he tries to generally and consistently apply his concept of a 'language game and its rules' to every corner of our ordinary language use that it becomes clear that we cannot do that without conceptual bankruptcy. The problems about rules, including Kripke's famous paradox, must have been realized by Wittgenstein during this process. Our next task is to explore the process of such thinking and to make these problems clear. To do that, let's turn to the initial 188 sections of Philosophical Investigations, which could be regarded as the textual reconstruction of the philosophical drama of this thinking process. ${ }^{17}$

The structure and contents of this initial part of Philosophical Investigations are so tricky that unacquainted naive readers may think that the point of these sections is to show Wittgenstein's new understanding of language in terms of his celebrated

15 That the criticism of Platonism is one important theme of Wittgenstein's thinking concerning rules does not seem to be generally recognized. One of few people who explicitly show this recognition is Crispin Wright. See C. Wright (1989), p.302.

${ }^{16}$ Wittgenstein (1969), pp.77-185. If we compare The Brown Book and Philosophical Investigations, we can find that the latter adds very little to the former with respect to the positive contents of the concept of language game. What the latter adds is the considerations concerning the problems of rules and the consequent various thoughts derived from them.

17 Thanks to the study of G.H. von Wright (von Wright (1982)) and newly discovered so-called Koder Nachlass, we can now quite safely infer that most of these sections were originally written in his lonely stay at Norway from November of 1936 to April of 1937 and that this drama happened during this period. For the detailed philological information about these documents, see Koder (1993). The most important documents in Koder Nachlass for our present discussion are MSS142 and 183. The former is the final draft for the initial 188 sections of P.I. and the latter is the diary Wittgenstein kept during that stay in Norway and some previous periods. It was published on 1997 as Wittgenstein (1997). Its English translation is Wittgenstein (2003). 
concept of 'language game' and to criticize his former view in the Tractatus from this new point of view. At least, I used to read them in such a way until I recognized the real significance of Kripke's interpretation. However, if this naive interpretation were right, the initial part must have ended at $\S 64$, for a short but adequate exposition of the concept of 'language game' is already given in $\S \S 1-25$, and his criticism of the Tractatus' view of language is given in the following $\S \S 26-64$. But in fact, the real philosophical thinking of Wittgenstein in this part starts at $\S 65$ and continues up to the end of this initial part as we will see in the following examination. Therefore the point of his philosophical thinking in this initial part cannot be a mere exposition of the concept of 'language game'. Its real point is the thorough critical investigation of the very concept of 'language game' itself and the presentation of the problems inherent in it that show its conceptual inadequacy. In other words, to question the adequacy of the very concept of a 'language game and its rules' is the whole point of the initial part of Philosophical Investigations. ${ }^{18}$

As is well known, this process of thinking is presented in the form of a dialogue with an imaginary interlocutor, who, I think, ought to be considered as another self of Wittgenstein rather than a hypothetical person who represents a certain philosophical position to be criticized. In $\S 65$, the critical thinking starts with Wittgenstein's presentation of the interlocutor's reasonable questioning of preceding descriptions of language through the concept of a 'language game', "Here we come up against the great question that lies behind all these considerations.-For someone might object against me: 'You take the easy way out! You talk about all sorts of language-games, but have nowhere said what the essence of a language-game, and hence of language, is...'" In the following sections, ${ }^{19}$ Wittgenstein presents what might be called a 'family resemblance solution' to the question of "What is a language game?" but apparently he didn't take it a valid or final answer. This is shown by the fact that he continues his critical consideration of the concept of a 'language game and its rules' even after his discussion about family resemblance. He continues his critical consideration because the real issue for him was not whether the concept of the game can be sharply defined or not, but whether we can apply the concept of the rule to our ordinary use of language at all. This issue is crucial since the concept of a 'language game' was originally meaningful for Wittgenstein only because we could express the regularities of our uses of language by means of its rules. Therefore, if it turned out that the concept of 'rules of a game' cannot literally apply to our uses of language, there will be no point of calling our linguistic activities the 'playing of a language game'. ${ }^{20}$ If this be the case, Wittgenstein would have to choose one of the following

18 This is what divides the initial part of P.I. and The Brown Book. See also note 16.

$19 \S \S 65-67$.

20 As we noted at notes 7 and 16, once Wittgenstein introduced the concept of language game to his consideration of language, the problems concerning the traditional 
two alternatives. If he respects the original formalist background of the concept of the game, he has to abandon the application of the concept of 'language game' to our ordinary uses of language. On the other hand, if he wants to keep that concept for our ordinary uses of language, he has to give the concept of 'rules of a game' a new meaning completely different from the original formalist one. This seems to be the situation Wittgenstein was facing when he wrote the following words of $\S 81$, “... in philosophy we often compare the use of words with games and calculi which have fixed rules, but cannot say that someone who is using language must be playing such a game."

During these strategic sections, Wittgenstein presents three problems about a language game and its rules one after another. As he goes along from one problem to another, he gradually moves away from the formalist's original understanding of a game and its rules and comes in need of a new concept of a 'game and its rules'. This is, at the same time, the process of his leaving Platonism and approaching skepticism. Let's look at those problems in turn.

The first problem about rules is presented in $\S \S 68-71$. We can find the solution to it in these sections, too. It is the problem of whether a game with incomplete rules can still be called a game or not. This is essentially the same problem as that of a vague concept, i.e. whether a vague concept can still be called a concept or not. He gave a positive answer to this problem. Games or language games don't have to be specified in all respects by definite rules as long as the practice of game-playing goes well without particular troubles, this is his new understanding of language game, and he denied Frege's understanding of 'concept' through it. ${ }^{21}$ 'This first problem is a relatively easy one while two other problems are far more difficult and are left unanswered in the initial part of Philosophical Investigations. The second problem is presented in $\S 82$. It is about what rules the speaker of a language is supposed to follow. If the use of a word is a playing of some language game, there should be a particular set of rules that define this language game. However, people who use words in their everyday life usually don't notice any such rules. ${ }^{22}$ The fundamental

concept of meaning became those concerning rules.

${ }^{21}$ See $\S 71$.

22 This is exactly the same problem as the one Noam Chomsky faced in the earlier stage of generative grammar in which the concept of rules plays the central theoretical role. As for an example of such a theoretical framework, see Chomsky (1965). In this earlier framework, Chomsky used the concept of phrase structure rules to capture the regularity shown by the contents of linguistic knowledge of native speakers. The problem is that there is no clear sense in which native speakers "follow" these rules in their ordinary use of language. He eventually solved the problem by abolishing the concept of rules in the new theoretical framework of generative grammar called "principles and parameters theory" and its latest version called "minimalist program". See Chomsky (1995), Chap. 1. In so far as we take linguistics as an inquiry of the biological basis for human language as Chomsky does now, it is clear that there is no use for 
problem here is that the analogy between game and language reaches its limit. The paradigmatic cases of the game from which this analogy started are games with explicit and fixed rules like chess or tennis. However, our uses of words are not governed by such rules except in some special areas like law or science. On the other hand, it is out of the question to call the observed regularities of speakers' behaviors the rules they follow in their language game. For if we are to call them rules of a game people follow, we would have to say that the sun and the planets are following the rules of Newtonian mechanics by the same token. We have to give up the analogy unless we form a new concept of 'rules of a language game' that is radically different from the explicit rules of a game like chess. ${ }^{23}$ The concept of 'following a rule' will play this role.

The third problem is the one Kripke dubbed a 'paradox'. It is concerned with the relationship between fixed formal entities such as forms, signs or rules on the one hand and human activities on the other. It is the problem expressed in the following question of $\xi 198,{ }^{24}$ "what has the expression of a rule - say a sign-post - got to do with my actions?" In a sense, the third problem has the same fundamental setting as the original problem Wittgenstein faced when he started to borrow the metaphor of a game from the formalist philosophy of mathematics. On both occasions, Wittgenstein's concern is the relationship between formal entities and human activities. Of course, there is a fundamental difference between those two occasions with respect to Wittgenstein's confidence about the ontological priority of formal entities. When Wittgenstein started to use the game metaphor, he put the priority on the side of the formal entities that are supposed to logically determine the forms and values of actual

the concept of rules in linguistics. In this sense, Chomsky's theoretical change since 1980's is correct and wise because it liberated him from unnecessary problems of rule. On the other hand, if we want to take social practices using language as the object of our investigation as Wittgenstein did, we cannot evade the problems of rules just by ignoring them. We have to solve them. It is what Wittgenstein tried to do in P.I. In this sense, I think, there is a neat division of labor between Chomsky after 1980's and late Wittgenstein in the filed of the study of language. The former focuses on the problem of natural foundations of human language while the latter concentrates on the aspect of language as a set of social practices. They investigate two different and complementary aspects of human language. Their programs would collectively complete our understanding of human language. So there is no conflict between their views of language, we need both to grasp the totality of phenomena called 'language'.

${ }^{23} \S 83$ may sound as if it offered an solution to the problem by assimilating two senses of German word 'Spiel' with each other, i.e. by assimilating the concept of game and that of children's play. However, it doesn't constitute any serious answer to the problem since the point of calling particular linguistic activities a language game is to see some order in them and the concept of 'children's play' does not contain this crucial element. That assimilation would lose this point.

${ }^{24}$ See also the following text: "But how can a rule show me what I have to do at this point?" $(\S 198)$ 
human activities and didn't show any doubt about this Platonistic understanding of language. On the other hand, his raising this problem as the third problem of rules in Philosophical Investigations means that he already came to question this ability of formal entities at this period. This is why the third problem of rules has the aspect of a skeptical paradox, which is expressed by the following famous passage of $\S 201$, "This was our paradox: no course of action could be determined by a rule, because every course of action can be made out to accord with the rule."

This third problem has the following skeptical implications for the philosophy of language as well as for the philosophy of mathematics. If the meaning of each linguistic activity of human beings is to be determined by the rules of language and if these rules have no ability to do so, as suspected by Wittgenstein, then no linguistic activity of human beings has definite meaning; this is the significance of the paradox for the philosophy of language, which was well captured by Kripke's work. This, however, seems not to be a serious threat to our practice of using language because the destructive conclusion (i.e. "no linguistic activity of human beings has definite meaning") does not follow if the first conditional clause (i.e. "if the meaning of each linguistic activity of human beings is to be determined by the rules of language") is dropped, and this clause does not seem so difficult to drop since our ordinary use of language is not generally considered as defined by a set of fixed rules. On the other hand, the paradox's implication for mathematics seems far more serious since to drop the corresponding conditional clause in mathematics is much more difficult. ${ }^{25}$ In order for mathematics to exist, there have to be mathematically valid activities of human beings such as counting, calculating or proving, and these activities are generally thought to be mathematically valid because they correspond to the mathematical rules or axioms that define what valid proofs are or what correct calculations are. However, if these rules actually have no such ability, then there would be no distinction between valid mathematical activities and random activities, in other words, no distinction between valid proofs, for example, as presented by Gödel and random sequences of symbols drawn by a child. This means that mathematics would lose its objectivity if Wittgenstein's doubt about rules is valid. I think that this serious aspect of paradox is not sufficiently captured by Kripke's work though he may have felt it. ${ }^{26}$ Wittgenstein raises the third problem twice in Philosophical Investigations; the first time, as a possible skepticism about the meaning of linguistic activities and,

${ }^{25}$ As for the asymmetry between the cases of linguistic expressions in general and those of mathematical expressions, see note 7 .

${ }^{26}$ That Kripke has felt some deep and unusual nature of Wittgenstein's paradox is indicated by his following words.

Wittgenstein has invented a new form of scepticism. Personally I am inclined to regard it as the most radical and original sceptical problem that philosophy has seen to date, one that only a highly unusual cast of mind could have produced. (Kripke (1982), p.60) 
the second time, as a specific skepticism about the objectivity of mathematics. Let's take a close look at each of them.

The third problem of rules applied to linguistic expressions in general may be considered as the reversal of the first problem. The first problem and Wittgenstein's answer to it imply that the completeness of the rules of a language game is not a necessary condition for a linguistic activity to have a definite meaning. One sceptical question naturally derived from this conclusion is, "Then, is the completeness of rules a sufficient condition for a linguistic activity to have a definite meaning?" What the following text of $\S 84$ presents is such a sequence of thoughts, ${ }^{27}$ "I said that the application of a word is not everywhere bounded by rules. But what does a game look like that is everywhere bounded by rules? whose rules never let a doubt creep in, but stop up all the cracks where it might? - Can't we imagine a rule determining the application of a rule, and a doubt which it removes - and so on?" Though this reasoning could present a serious threat to our concept of the meaning of speech, we don't feel the seriousness of the problem here. Apparently, one reason is that the way the doubt is presented, i.e., asking for another rule for the application of a rule endlessly is too general. There is a sharp contrast between this case and Wittgenstein's presentation of the same problem in mathematics. In the latter, he presents it in a very concrete form, probably in the most concrete form we could imagine. It is why we feel that this is a problem, to quote Kripke's expression, "that only a highly unusual cast of mind could have produced." ${ }^{28}$ Let's turn to the case of mathematics.

Wittgenstein's third problem of rules applied to mathematics is presented in $\S \S$ 185--188, in which a strange student is introduced who is given an order to continue the series of numbers each of which is 2 larger than the previous one, i.e. the series of even numbers, and answers, "2000, 2004, 2008,.." though he gave correct answers up to 2000 . We can find a similar example of the same problem at $\S 5$ of the second part of The Brown Book ${ }^{29}$ in which a student is asked to continue the series of natural numbers under the order of "Plus 1!" and answers, "100, 102, 104..." From these cases, ${ }^{30}$ I think, it is clear that what Wittgenstein specifically intends to do here is to

27 See also $\S \S 84-88$

${ }^{28}$ Kripke (1982), p.60.

${ }^{29}$ Wittgenstein (1969), pp.141-143.

30 There are, at least, three more occasions where Wittgenstein presented essentially the same paradox as the following.

R. Rhees, 'R. Rhees' Lecture Notes of the Lectures on the Language of Sense Data and Private Language', Wittgenstein (1993), p.354.

Wittgenstein (1978), pp.36-37.

Wittgenstein (1989), pp.26-27, 58-59, 84-85, 123-128.

All these occurrences of the paradox were in the period 1934-1939 and the paradox seems to stop appearing in Wittgenstein's texts after Wittgenstein presented the solution by means of the concept of "following a rule" in 1944. These facts suggest a following picture of P.I. Wittgenstein was heavily occupied with the problems of rules 
question the objectivity of such concepts as 'continuing a regular series of numbers in the same way indefinitely' or 'keeping the regularity of a series indefinitely'. In other words, he questions the very objectivity of the concept of 'mathematical regularity' or the objectivity of the very concept of 'natural numbers' as the foundation of mathematics. ${ }^{31}$ In his presentation of the problem, Wittgenstein convincingly shows us that we cannot show or demonstrate or explain the objectivity of these concepts unless we already presuppose it. This is shown by the following intriguing passage of $\S 185$, "We say to him: "Look what you've done!" - He doesn't understand. We say: "You were meant to add two: look how you began the series!" - He answers: "Yes, isn't it right? I thought that was how I was meant to do it." "The point here is that our basic mathematical concepts such as 'regularity', 'same', 'in the same way indefinitely' or 'natural numbers' form a closed conceptual circle so that we cannot explain any of them without presupposing the others. ${ }^{32}$ So it is conceivable that some intellectual entities have a non-standard understanding for each of them and apply these non-standard concepts consistently. They may have a non-standard mathematics that is completely beyond our imagination but we cannot show our mathematics is right and theirs is wrong. Of course, the scope of this argument is by no means limited to mathematics. What Wittgenstein shows is that the concept of 'language game' or 'following a rule' cannot be defined by a set of exact and explicit rules even in the area of mathematics which is supposed to exemplify ideally well defined language games, let alone in the area of ordinary language. Thus he succeeds in presenting a very strong case for both general skepticism about language games and special skep-

in the period 1934-1939 because of his adoption of the concept of language game as the core of his philosophical thinking and his thinking concerning these problems in this period is shown in the first 188 sections of P.I. His solution of these problems by means of his new understanding of human linguistic behaviors ('language as practice and institution') formulated on 1944 is shown in $\S \S 198-243$ and the subsequent sections of P.I. are devoted to the attempts to apply this new concept of language to the part of language that seems unsuitable for such a concept, i.e. various psychological terms.

In any case, it seems clear that the problems of rules, including the paradox, play the central role in the formation of later Wittgenstein's philosophical thinking. From such a point of view, Kripke is absolutely right in emphasizing the importance of the paradox. We cannot separate the paradox and the problems of rules from the philosophy of later Wittgenstein simply by denying the importance of the paradox as McGinn does (McGinn (1984), p.68, p.68 note 11, p.70 note 14).

${ }^{31}$ If Wittgenstein's intention for constructing the paradox of rules is, as we suppose, to question the very objectivity of mathematical regularity, his use of the cases of number series in the paradox is essential for his philosophical project. If our interpretation of Wittgenstein is correct, Kripke's replacing Wittgenstein's original case of number series with that of addition of arbitrary two numbers is misleading since the concept of addition is derived from that of natural numbers.

${ }^{32}$ See $\S 208$. 
ticism about mathematics. This is the situation described as 'our paradox' in the following passage of $\S 201$ of P.I. that became the focus of many discussions after Kripke's work.

This was our paradox: no course of action could be determined by a rule, because every course of action can be made out to accord with the rule. The answer was: if everything can be made out to accord with the rule, then it can also be made out to conflict with it. And so there would be neither accord nor conflict here. $(\S 201)$

Wittgenstein's solution to this paradox is based on a new concept of 'following a rule', which is introduced in the next paragraph of $\S 201$. It says, "What this shows is that there is a way of grasping a rule which is not an interpretation, but which is exhibited in what we call 'following the rule' and 'going against it' in actual cases ("von Fall zu Fall der Anwendung" in German)." In this passage, he uses the expression 'following the rule' as a kind of proper name by putting it between quotation marks. Then, he adds the following words about this concept in $\S 202$, "Therefore "following the rule' is a practice." 33 What is this new concept of 'following a rule' ? and how can it be a solution to his problems about rules? They are the final questions of our inquiry.

3.

Wittgenstein gives his solution to these problems in $\S \S 198-242$. Here I would like to make a parenthetical remark on the text of Philosophical Investigations to remind the reader of one important historical fact about it. Wittgenstein wrote these sections on 'following a rule' seven years after he had written the initial 188 sections. As is well known among the researchers of Wittgenstein's texts, this fact was revealed by G.M. von Wright's critical study of Wittgenstein's texts. ${ }^{34}$ To recognize it is crucial for the proper understanding of Philosophical Investigations, for it means that he did not compose its initial 242 sections as a single unified discourse consisting of a paradox and its solution as Kripke probably supposed in his book. ${ }^{35}$ It rather

33 The translation is mine. The original German text is: "Darum ist 'der Regel folgen' eine Praxis."

34 See notes 8 and 17.

35 Kripke interprets Wittgenstein's solution of the paradox by means of the concept of 'following a rule' as a sceptical solution in the sense that it denies the reality of rules or rule-following or 'meaning'. Pace Kripke, as will be shown in the following discussions, Wittgenstein's solution is clearly not a sceptical one since it shows us a new sense of reality for rules. One reason of Kripke's misunderstanding of Wittgenstein's solution seems to be his lack of information about the origin and structure of the texts of P.I. revealed by G.H. von Wright (von Wright (1982), pp.111-136). See also notes 
indicates that he had initially only realized the problems of rules and later discovered their solution, probably as the result of the hard thinking of seven years. During this period, he extensively wrote on mathematics. Those materials were posthumously published as Remarks on the Foundations of Mathematics. ${ }^{36}$ Now let me return to the main story.

In these sections, Wittgenstein gives the solution rather as a description of his new understanding of human linguistic activities than as a straightforward solution to the paradox. The essential element of this new understanding that differentiates it from the older one is the reversed order of ontological priority between fixed formal entities and our actual linguistic activities. In the previous period, in which he wrote the initial 188 sections, the existence of rules was presupposed in his thinking and the question of how our actual activities could conform to these rules puzzled him. In the new understanding, on the contrary, there are thought to be some primitive linguistic activities that are prior to the existence of any fixed rules. All rules are thought to be derived from these activities or defined by means of the rules derived from them. The key expression 'following a rule' should be considered as the proper name Wittgenstein invented to designate these primitive linguistic activities. ${ }^{37,38}$ This is, I think,

8 and 17.

${ }^{36}$ Wittgenstein (1978).

${ }^{37}$ These primitive linguistic activities are what is called 'practice '('Praxis' in German) by Wittgenstein ( $\S 202)$. They should not be identified with any sets of dispositions or natural propensities since they are 'social' practices that necessarily contain the normative dimension. An activity's being a practice in this sense means that there is a set of judgments shared by the community in which the practice is practiced concerning the correctness of actions belonging to the practice. It is only the concept of 'following a rule' in this normative sense that can serve as a solution to Wittgenstein's paradox. If we, against this proper interpretation of Wittgenstein's concept of 'practice', interpret the concept of 'following a rule' by means of dispositions as McGinn does (McGinn (1982), pp.72-73, 76), the paradox remains unsolved because the difference between us and that strange student in Wittgenstein's paradox is the difference of two different dispositions, i.e. a disposition to give an answer '2002' in response to the order ' $2000+2$ ' and another disposition to give a different answer '2004' to the same order and there is no sense in telling which disposition is correct one as long as we consider only dispositions since they probably are corresponding to two dispositions to respond differently to the question, "What is the next nuber of 1000?" (we answer '1001' and that student answers '1002') and the concept of 'next number' cannot be defined unless we presuppose such concepts as 'to continue a series of numbers in the same way' or its cognates, whose contents are questioned in the paradox. What we have to do to solve the paradox is to show the way to tell our answer is correct. What we need for this is the concept of practice that contains the dimension of 'correctness of action'. What we ultimately need to solve the paradox is the concept of 'our actual practice to which we actually have full and serious commitment', which serves as the ultimate standard for correctness in our actual practice including philosophical discussions.

McGinn might reply to such a criticism by saying that the paradox of rule is not a 
what is meant by the sentence, "Therefore 'following the rule' is a practice." In other words, what is called 'following a rule' by him at this period is not an act of following a particular rule but a group of indefinable primitive activities or practices prior to any rules.

As the examples of these primitive linguistic activities, Wittgenstein gives such activities as 'obeying an order' (§ 206), 'giving an order' (§ 199), 'reporting' (§ 199), 'continuing a series of numbers' ( $\S 208,212-4,218-9)$, 'calculating' (§ 233-6), 'giving the name of an indicated basic color such as blue or red' ( $\$ 238)$, and 'picking out a named basic color such as blue or red' ( $\S 239)$. According to his new understanding of human linguistic activities, we are first engaged in these primitive linguistic activities without any definition or specification by means of fixed rules. All normal human beings share the abilities for these activities in common as a matter of fact. ${ }^{39}$ These activities serve us as a fixed measure for the most fundamental non-finite concepts such as 'same', 'regular', 'random', 'uniform', 'natural', or 'in the same way indefinitely'. They are the most basic and primitive language games that human beings actually play and all other language games that human beings are actually or possibly playing are defined through these concepts or explicit rules that presuppose them and, as such, they are applicable to indefinitely new and many cases. As far as we share these primitive activities or language games and concepts formed through them, we can define any complicated language games without the possibility of facing radically different non-standard interpretations of a rule. Thus there would be no paradox. On the other hand, there is no hope of our sharing any common language game, however explicitly and minutely we may define it by means of fixed rules unless we previously share these primitive activities since these rules will not get any

real problem for Wittgenstein and that we are allowed to interpret Wittgenstein naturalistically in terms of dispositions since we do not have to solve the paradox (McGinn (1982), p.68, p.68 note 11, p.70 note 14). However, the facts about Wittgenstein's text don't support McGinn's denial of the importance of the paradox for Wittgenstein as shown at note 30. Any attempt to interpret P.I. naturalistically like McGinn's seems to have to deny the significance of the paradox of rule exhibited in $\S 185-188$ for Wittgenstein. This means that any type of naturalistic interpretation of P.I. is not supported by the facts about Wittgenstein's texts.

38 That these primitive activities are practices in the sense defined at the previous note means that they are also language games in the most fundamental Wittgensteinian sense of the words. In other words, the three expressions, i.e. "primitive linguistic activity', 'primitive practice', and 'primitive language game', are mutually exchangeable here.

${ }^{39}$ Here, it is important to distinguish the primitive practices which are essentially communal phenomena (e.g. that of counting by means of natural numbers) and the individual human beings' innate abilities that serve as the biological foundation for those practices (e.g. the ability or disposition to extend natural number series indefinitely under a certain training). See note 40 for more detailed discussion about their relationship. 
fixed interpretations. This is how the paradox is solved by the concept of 'following a rule.' It also solves the second problem of rules, i.e. the question of "What rules are we following when we use language in our ordinary life?" The answer is, we are not following any particular rules but are engaged in the activities or practices called 'following a rule in speaking'. When we call something red or count the number of objects, we are not following any particular rules but we are engaged in the primitive practices or language games such as "giving the names of basic colors' and 'counting the number of objects'. Of course, we can formalize these practices and construct the rules of these games but the meaning and existence of these rules are derived from those primitive practices in the sense that we cannot get any fixed interpretation of these rules unless we have already practiced these primitive language games without the aid of any rules. Metaphysically speaking, Wittgenstein's solution of the paradox means his absolute and complete negation of Platonism as well as of formalism in all areas including mathematics. We may say that he had overcome both Platonism and skepticism by finding the new concept of 'following a rule'.

Let's see the specific implication of Wittgenstein's new understanding of linguistic activities for the philosophy of mathematics before I end my paper. According to this new understanding, all concepts, all axioms and all rules in mathematics are actually founded on such basic mathematical concepts as 'same', 'regular', 'random', 'uniform', 'mathematically natural' or 'in the same way indefinitely', or defined by the concepts, axioms, or rules that presuppose them. The concrete contents of these basic concepts in mathematics are given not by any explicit definitions but by a small number of primitive linguistic activities or practices fundamental for mathematics. They are what might be called 'following a rule in mathematics'. They are the ultimate standard of objectivity in mathematics. One of them is 'counting'. By sharing the common practice of counting as a matter of fact, ${ }^{40}$ all human beings are able

${ }^{40}$ For a community to share the common practice of counting means, 1) there is almost complete agreement among all the adults in the community with respect to the question "what is the next number?" for indefinitely many cases, 2) virtually all new born babies in the community can be brought into this agreement by means of an appropriate training of a certain period at a certain age except pathological cases, and 3) virtually all adults recognize these facts of agreement and consider them as 'self evident' as well as constituting 'what is right' in their practice of counting.

It is apparent that there exists a certain natural or genetic foundation for this universal agreement among human beings. From such a point of view, that strange student of Wittgenstein's paradox can be described as 'lacking this common genetic foundation for counting'. Wittgenstein's following words indicate that he considered the case in such a way.

Such a case would present similarities with one in which a person naturally reacted to the gesture of pointing with the hand by looking in the direction of the line from finger-tip to wrist, not from wrist to finger-tip. ( $(\$ 185)$

It is extremely important here to notice that the existence of the natural foun- 
to share the concept of 'natural numbers' or 'the most regular series of numbers' and construct indefinitely complex mathematical objects out of it. In the area of mathematics dealing with these objects (roughly speaking, algebra), the objectivity of mathematics is based on our common activity of counting or our agreement in the practice of counting. So, we can say to that strange student something like this, "Counting' is the name of our most basic mathematical activity. What you are doing is not counting. That is why your answer is mathematically wrong." An interesting question for us is, "How many other basic mathematical activities or practices do we humans share either actually or potentially?" 41 It is an interesting question because there should be as many objective areas of mathematics as the number of these primitive activities. Unfortunately, most examples Wittgenstein gives in Philosophical Investigations are cases of continuing a series or calculating, both of which are closely related to counting. We have to discover the answer to that question by ourselves. I would like to leave it to the mathematicians.

\section{References}

Boghossian, P.A. (1989) "The Rule-Following Considerations", Mind 98, pp.507-549.

dation for counting is not same as that of the practice of counting. The former is a natural phenomenon while the latter is a social phenomenon. At a certain period in their evolutional history, human beings must have started to utilize that foundation for forming a social practice of counting for the first time since it is highly implausible that the ability to produce the series of natural numbers indefinitely had any use under the environment in which human species was originally formulated. What is essential for the social practice of counting is that we can say what is right and what is wrong in this practice, in other words, there is the normative dimension in this activity. Otherwise, it is not a practice, but a wide spread form of behaviors like fashion. In this sense, the practice of counting essentially includes the normative dimension and can not be equated with any set of natural dispositions or propensities though the latter are the natural foundation or condition for the former. See also note 37. Wittgenstein explicitly mentions this distinction between the natural and the normative by using the phrases "causally determined" and "logically determined" as the following.

But what is the purpose of that symbolical proposition? It was supposed to bring into prominence a difference between being causally determined and being logically determined. (§ 220)

In the lectures on the foundations of mathematics given on 1939, Wittgenstein extensively discussed about the normative element of mathematics and debated Alan Turing on this issue. See Wittgenstein (1989), lectures X, XI, pp.92-111.

41 That human beings potentially share a mathematical practice means that all human beings share a certain biological innate ability that is not yet exploited for any actual mathematical practice but can produce an agreement in the behaviors of human beings and can become the biological basis for a future practice of human being that we inclined to call 'mathematical' because of its resemblance to actual mathematical practices. 
Chomsky, N. (1965) Aspects of the Theory of Syntax, MIT Press.

Chomsky, N. (1995) The Minimalist Program, MIT Press.

Goldfarb, W. (1985) "Kripke on Wittgenstein on Rules", The Journal of Philosophy 82, pp.471-488.

Kikai, A. (2003) Witogenshutain-wa Ko Kangaeta (Thus Thought Wittgenstein), Kodansha Publishing.

Koder, J. (1993) "Verzeichnis der Schriften Ludwig Wittgensteins im Nachlass Rudolf und Elizabeth Koder", Mitteilungen aus dem Brenner-Archiv 12, pp.53-54.

Kripke, S.A. (1982) Wittgenstein on Rules and Private Language, Harvard University Press.

Matsuzaka, Y. (1995) "Kisoku-no Ninshikiron (Epistemology of Rules)", in T. Iida (ed.) Witogenshutain Dokuhon (Readings on Wittgenstein), Hosei University Press.

McGinn, C. (1984) Wittgenstein on Meaning, Basil Blackwell.

von Wright, G.H. (1982) Wittgenstein, Basil Blackwell.

Wittgenstein, L (1958) Philosophical Investigations, (2 ${ }^{\text {nd }}$ ed.), translated by G.E.M. Anscombe, Basil Blackwell.

Wittgenstein, L (1969) The Blue and Brown Book, (2 ${ }^{\text {nd }}$ ed.), Basil Blackwell.

Wittgenstein, L (1978) Remarks on the Foundations of Mathematics, (3 ${ }^{\text {rd }}$ ed.), translated by G.E.M. Anscombe.

Wittgenstein, L (1979) Wittgenstein and the Vienna Circle, recorded by Friedrich Waismann, edited and translated by Brian McGuiness, Basil Blackwell.

Wittgenstein, L (1989) Wittgenstein's Lectures on the Foundations of Mathematics Cambridge 1939, edited by Cora Diamond, Chicago University Press.

Wittgenstein, L (1993) Ludwig Wittgenstein Philosophical Occasions 1912-1951, edited by James Klagge and Alfred Nordmann, Hackett.

Wittgenstein, L (1997) Ludwig Wittgenstein Denkbewegungen Tagebücher 1930-1932 19361937, edited by Ilse Somavilla, Haymon Verlag.

Wittgenstein, L (2000) Wittgenstein's Nachlass, Bergen Electronic Edition, Oxford University Press.

Wittgenstein, L (2003) Movements of Thought: Diaries 1930-1932, 1936-1937 (English translation of Wittgenstein (1997)), translated by Alfred Nordmann, in James Klagge and Alfred Nordmann (eds.) Ludwig Wittgenstein Public and Private Occasions, Rowman \& Littlefield.

Wright, C (1984) "Kripke's Account of the Argument against Private Lanuage", The Journal of Philosophy 81, pp.759-778.

Wright, C (1989) Critical Notice (a review of McGinn (1984)), Mind 98, pp.289-305. 